\title{
An Experimental Investigation of Modal Densities of Composite Honeycomb Sandwich Cylindrical Shells
}

\author{
K. Renji \\ Advanced Technology Development Group, UR Rao Satellite center, ISRO Vimanapura Post, Bangalore, India \\ 560017.
}

\author{
S. Josephine Kelvina Florence and Sameer Deshpande \\ Structures Group, UR Rao Satellite center, ISRO Vimanapura Post, Bangalore, India 560017.
}

(Received 23 May 2019; accepted 9 February 2020)

\begin{abstract}
Honeycomb sandwich composite cylindrical shells are widely used in aerospace structures. Experimentally observed modal densities of such shells are not reported. In this work, modal densities of a typical honeycomb sandwich composite cylinder are obtained experimentally by measuring the drive point admittance. The results are in good agreement with those estimated theoretically that incorporated transverse shear deformation. Its limitations at higher frequencies are investigated and the frequency beyond which the estimation is in error is determined. The results provide an example to prove the need for measuring the imaginary part of the driving point admittance and using it in the determination of the modal densities of honeycomb sandwich-type structures. Experiments are carried out with two boundary conditions for the cylinder and the results provide experimental evidence for the fact that the modal densities at high frequencies do not depend on the boundary conditions. At higher frequencies, it is expected that both of the face sheets vibrate independently. This frequency can be approximately estimated as the fundamental bending mode frequency of the wall of the honeycomb core. The modal density determined through the measured driving point admittance will have a sharp reduction at this frequency and this feature can be used in identifying this phenomenon. The experimental results are in very good agreement with the above results.
\end{abstract}

\section{NOMENCLATURE}

$Y_{a} \quad$ Actual admittance

$Y \quad$ Admittance

$Y_{M} \quad$ Admittance of the impedance head and the attachment elements

$A \quad$ Area of the cylinder

$\phi_{f f} \quad$ Auto spectral density of the force

$<\quad$ Average over the space

$m \quad$ Axial half wave number

$D_{i j} \quad$ Bending stiffness terms

$n \quad$ Circumferential full wave number

$c, s \quad \operatorname{Cos} \theta, \sin \theta$

$\phi_{f v} \quad$ Cross spectral density between the force and the velocity

$\omega \quad$ Excitation frequency in $\mathrm{rad} / \mathrm{s}$

$A_{i j} \quad$ Extensional stiffness terms

Im Imaginary part

$L \quad$ Length of the cylinder

$m \quad$ Mass of the structure

$\rho \quad$ Mass per unit area of the cylinder

$Y_{m} \quad$ Measured admittance

$n(f) \quad$ Modal density

$a \quad$ Radius of the cylinder

Re Real part

$N \quad$ Shear rigidity of the shell

\section{INTRODUCTION}

Honeycomb sandwich cylindrical shells having face sheets made of composite material are being used in many aerospace structures. Responses of such structures in their higher order modes are determined using Statistical Energy Analysis (SEA). ${ }^{1,2}$ In SEA, the system under consideration is divided into various subsystems. The energies in the subsystems are controlled by the SEA parameters modal density, internal loss factors, and coupling loss factors. ${ }^{3,4}$ The modal density is one of the important parameters of the structure to be considered in the SEA-based calculations.

Modal density is the number of natural modes in unit frequency band and it is normally estimated analytically. There are several studies reported on the modal densities of structural elements and they are compiled by Hart and Shah. ${ }^{5}$ Wilkinson $^{6}$ and Szechenyi ${ }^{7}$ derived expressions for modal densities of cylindrical shells and the work by Langley ${ }^{8}$ presented them in the form of elliptical integrals. All the above works were on isotropic thin cylinders. Maymon, ${ }^{9}$ and Ramachandran and Narayanan ${ }^{10}$ studied the effect of stiffeners on the modal density of isotropic cylindrical shells. Finnvedan presented a finite element-based approach to estimate the modal density of shells. ${ }^{11}$ Elliott, ${ }^{12}$ Williams and Banerjee, ${ }^{13}$ and Mohammad H. Farshidianfar et al. ${ }^{14}$ discussed alternate methods to evaluate the modal density of circular cylindrical shells but it is applicable only to isotropic shells. 
Modal densities of orthotropic structures were discussed by Elishakoff ${ }^{15}$ on spherical structure and Langley ${ }^{16}$ on panels. Though the works by Chronopoulos et al. were on the vibro-acoustic response of composite shells using statistical energy analysis, no expressions were presented for modal densities. ${ }^{17,18}$ Josephine and Renji derived expressions for determining the modal densities of thin composite cylindrical shells. ${ }^{19}$ In honeycomb sandwich construction, the transverse shear deformation plays an important role. Hence, Florence et al. incorporated transverse shear deformation and obtained an expression for determining the modal density of a composite cylindrical shell. ${ }^{20}$

Though the expressions for determining the modal densities of composite cylinders are available in the literature, experimentally observed modal densities of such cylinders are not yet reported. The objective of the present work is to determine, experimentally, the modal densities of a typical composite honeycomb sandwich cylinder and compare them with the results using the expressions derived in the earlier works.

The modal densities are determined experimentally through an elegant method introduced by Clarkson by measuring the driving point admittances. ${ }^{21}$ Subsequently, Clarkson and Pope demonstrated this approach for plates and cylinders. ${ }^{22,23}$ Brown suggested several measures to improve the experimental determination of the modal densities. ${ }^{24}$ A major issue is the error in the measured results due to the admittance of the impedance head and the attachment elements used in the experiment. To account for this error, Brown and Norton introduced a correction factor. ${ }^{25}$

While determining the modal densities of honeycomb sandwich-type structures researchers faced additional difficulties. ${ }^{26,27}$ In another work, when this method was applied to composite honeycomb sandwich panels, the experimental results were not satisfactory. ${ }^{28}$ To address this issue, Renji modified the correction factor to take into account the admittance of the impedance head and the attachment elements and showed that in applying these new corrections the modal densities of honeycomb sandwich-type structures could be determined accurately. ${ }^{29}$ No experimental results are further reported on the modal densities of honeycomb sandwich-type structures. As the structure considered here is a honeycomb sandwich shell, the present work serves as another example for the verification of those findings.

It is well known and proved analytically that the modal density at higher frequencies is insensitive to the boundary conditions. But no experimental results of practical structures are reported on this aspect. During the present experimental investigation, the modal densities of the composite cylinder are determined with two boundary conditions.

Therefore, the present work provides experimentally observed modal densities of composite honeycomb sandwich cylindrical shells and their comparison with those estimated using the expressions derived earlier. It helps in knowing the influence of transverse shear deformation on the modal densities of such shells. The present work provides an additional example for the correction factors that need to be applied while measuring the driving point admittance and proves the method- ology of experimentally determining the modal densities of honeycomb sandwich-type structures. The present investigations also provide experimental evidence for the influence of the boundary conditions on the modal densities. It is expected that at higher frequencies both the face sheets vibrate independently. A methodology to approximately estimate this frequency is presented and proved through experiments. Characteristics of the modal density of honeycomb sandwich panels at high frequencies, determined through measuring the driving point admittance, are presented.

\section{EXPERIMENTAL METHODOLOGY}

Modal density was determined experimentally from the measured driving point admittance. ${ }^{21}$ The driving point admittance was the ratio of the Fourier Transform of the driving point velocity to the Fourier Transform of the driving force. The driving point admittance, denoted by $Y$ was thus be obtained from:

$$
Y=\frac{\phi_{f v}}{\phi_{f f}} .
$$

The modal density, denoted by $n(f)$, was then obtained from the driving point admittance as:

$$
n(f)=4 m<\operatorname{Re}(Y)>_{a} ;
$$

where $m$ was the mass of the structure and $\langle\operatorname{Re}(Y)\rangle_{a}$ was the drive point admittance averaged over several locations.

It was reported by Clarkson and Pope that the measured driving point admittance and hence, the measured modal densities were influenced by the admittance of the impedance head and the attachment elements. ${ }^{23,23}$ To take care of this effect, the correction factor given below was suggested by Brown and Norton: ${ }^{25}$

$$
Y_{a}=\frac{Y_{m}}{\left\{1-\frac{Y_{m}}{Y_{M}}\right\}} ;
$$

where $Y_{a}$ was the actual admittance and $Y_{m}$ was the measured admittance. The parameter $Y_{M}$ was the admittance of the impedance head and the attachment elements, which could be determined by exciting the impedance head and the attaching stud alone. If $M$ was the mass of the impedance head and the attachment elements, its admittance was given by:

$$
Y_{M}=\frac{1}{j \omega M} \text {. }
$$

Using Eq. (4) in Eq. (3) and as the real part of the admittance only was measured:

$$
Y_{a}=\frac{\operatorname{Re}\left(Y_{m}\right)}{\left\{1-j \omega M \operatorname{Re}\left(Y_{m}\right)\right\}} .
$$

Taking the real part of $Y_{a}$, Eq. (5) became

$$
\operatorname{Re}\left(Y_{a}\right)=\frac{\operatorname{Re}\left(Y_{m}\right)}{\left\{1+\left[\omega M \operatorname{Re}\left(Y_{m}\right)\right]^{2}\right\}} .
$$

Though Eq. (6) gave good results for thin structures, when applied to the honeycomb sandwich panels, they were not satisfactory. ${ }^{26-28}$ Renji demonstrated that it was also necessary to 


\begin{tabular}{l}
\hline \hline Table 1. Elastic moduli of materials \\
\begin{tabular}{|c|c|c|c|c|c||}
\hline Material & $\begin{array}{c}E_{l l} \\
\left(\mathrm{~N} / \mathrm{m}^{2}\right)\end{array}$ & $\begin{array}{c}E_{t t} \\
\left(\mathrm{~N} / \mathrm{m}^{2}\right)\end{array}$ & $\mu_{l t}$ & $\begin{array}{c}G_{l t} \\
\left(\mathrm{~N} / \mathrm{m}^{2}\right)\end{array}$ & $\begin{array}{c}\text { Density } \\
\left(\mathrm{kg} / \mathrm{m}^{3}\right)\end{array}$ \\
\hline $\begin{array}{c}\text { M18/M5J } \\
\text { UD }\end{array}$ & $2.15 \mathrm{E}+11$ & $6.6 \mathrm{E}+9$ & 0.23 & $3.9 \mathrm{E}+9$ & 1600 \\
\hline $\begin{array}{c}\text { M18/43090 } \\
\text { BD }\end{array}$ & $1.47 \mathrm{E}+11$ & $1.47 \mathrm{E}+11$ & 0.03 & $4.0 \mathrm{E}+09$ & 1660 \\
\hline
\end{tabular}
\end{tabular}

incorporate the imaginary part of the measured admittance in determining the real part of the actual admittance. ${ }^{29}$

The actual admittance that incorporated the imaginary part of the measured admittance was given by:

$$
\begin{aligned}
Y_{a} & =\frac{\operatorname{Re}\left(Y_{m}\right)+j \operatorname{Img}\left(Y_{m}\right)}{1-j \omega M\left[\operatorname{Re}\left(Y_{m}\right)+j \operatorname{Img}\left(Y_{m}\right)\right]} ; \\
Y_{a} & =\frac{\operatorname{Re}\left(Y_{m}\right)+j \operatorname{Img}\left(Y_{m}\right)}{1+\omega M \operatorname{Img}\left(Y_{m}\right)-j \omega M \operatorname{Re}\left(Y_{m}\right)} .
\end{aligned}
$$

From Eq. (8), the real part of the actual admittance was:

$$
\operatorname{Re}\left(Y_{a}\right)=\frac{\operatorname{Re}\left(Y_{m}\right)}{\left[1+\omega M \operatorname{Img}\left(Y_{m}\right)\right]^{2}+\left[\omega M \operatorname{Re}\left(Y_{m}\right)\right]^{2}} .
$$

\section{DETAILS OF THE CYLINDER}

The structural details of the cylinder used for the experiment are given here:

$\begin{array}{ll}\text { Length of the cylinder: } & 1.485 \mathrm{~m} \\ \text { Radius of the cylinder: } & 0.597 \mathrm{~m} \\ \text { Area of the cylinder: } & 5.578 \mathrm{~m}^{2} \\ \text { Mass per unit area: } & 1.72 \mathrm{~kg} / \mathrm{m}^{2} \\ \text { Face sheet thickness: } & 0.290 \mathrm{~mm} \\ \text { Face sheet material: } & 4 \text { layers of CFRP: } \\ & \left(0 / 90^{\circ} / 35^{\circ} / 0^{\circ} /-35^{\circ}\right) \\ \text { Core material: } & \text { Aluminium honey comb } \\ \text { Core height: } & 12 \mathrm{~mm} \\ \text { Core density: } & 32 \mathrm{~kg} / \mathrm{m}^{3} \\ \text { Core shear modulus: } & 1.4 \times 10^{8} \mathrm{~N} / \mathrm{m}^{2} \\ \text { Shear rigidity: } & 17.6 \times 10^{5} \mathrm{~N} / \mathrm{m} .\end{array}$

The elastic properties of the constituent materials of sandwich construction are given in Tables 1 and 2, respectively. The stiffness of the composite sandwich is presented in Table 3.

\section{EXPERIMENTAL RESULTS}

\subsection{Test Setup}

The modal density was determined experimentally from the spatial average of the driving point admittance at various locations.

In the present work, the cylinder was excited sequentially at 3 locations and the driving point admittances at each location were measured. The spatial average of the driving point admittances was obtained from which the modal density was determined using Eq. (2). Figure 1 shows a photograph of the cylinder under test. The cylinder was supported at two locations, which were at its circumference and they were about a distance of $L / 6$ from the two edges. The driving point locations are shown in Fig. 2.

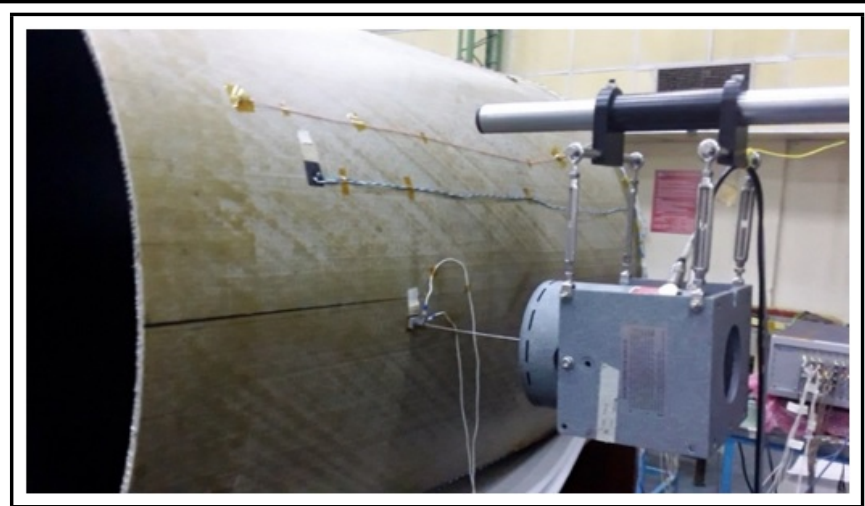

Figure 1. Photograph of the test setup.

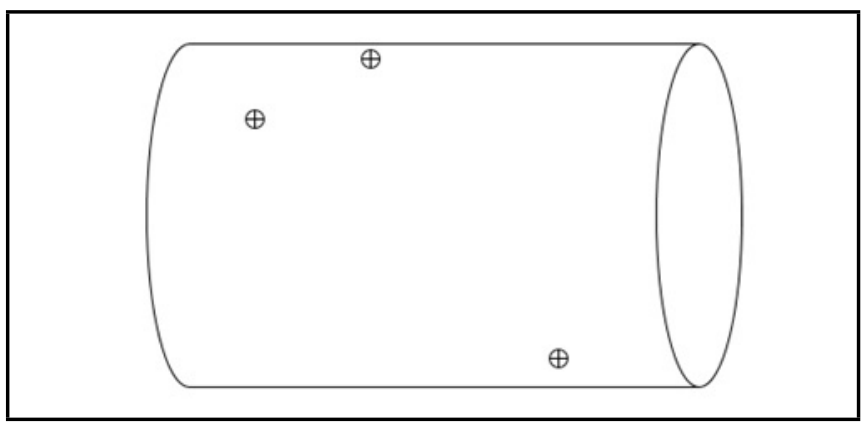

Figure 2. Driving point locations

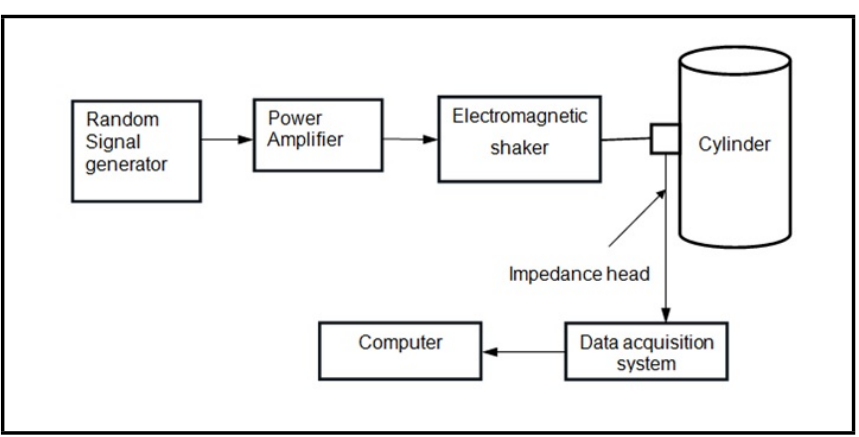

Figure 3. Block diagram of the test set up.

A Gaussian random signal was applied to the power amplifier of the shaker and the amplified signal was applied to the shaker. The shaker was connected to the cylinder through a stringer. The impedance head placed between the shaker and the cylinder measured force and the acceleration at the driving points.

The random excitation applied was in the frequency range $20-4000 \mathrm{~Hz}$. The force at the driving point and the acceleration at the driving point were measured. They were acquired with a sampling rate of $25.6 \mathrm{kHz}$, which allowed a maximum frequency range of $4000 \mathrm{~Hz}$. The number of frequency lines selected was 20, resulting in a resolution of $200 \mathrm{~Hz}$. The Hanning window was applied.

A block diagram of the measurement setup is shown in Fig. 3.

The correction factors as discussed in section 2 were applied to determine the actual driving point admittance. For this, the impedance head and the attachment element alone, without connecting to the structure, was driven. Based on the 
Table 2. Elastic moduli of core

\begin{tabular}{|c|c|c|c|c|c|c|c|}
\hline Material & $E_{l l}\left(\mathrm{~N} / \mathrm{m}^{2}\right)$ & $E_{w w}\left(\mathrm{~N} / \mathrm{m}^{2}\right)$ & $\mu_{l t}$ & $G_{l w}\left(\mathrm{~N} / \mathrm{m}^{2}\right)$ & $G_{l t}\left(\mathrm{~N} / \mathrm{m}^{2}\right)$ & $G_{w t}\left(\mathrm{~N} / \mathrm{m}^{2}\right)$ & Density $\left(\mathrm{kg} / \mathrm{m}^{3}\right)$ \\
\hline Low density Core & $1.00 \mathrm{E}+04$ & $1.00 \mathrm{E}+04$ & 0.3 & $1.00 \mathrm{E}+04$ & $1.4 \mathrm{E}+08$ & $1.4 \mathrm{E}+08$ & 32 \\
\hline
\end{tabular}

Table 3. Stiffness of CFRP Sandwich

\begin{tabular}{||c|c|c|c|c|c|c||}
\hline & \multicolumn{3}{|c|}{ Membrane stiffness $A_{i j}$} & \multicolumn{3}{c|}{ Bending stiffness $D_{i j}$} \\
\hline Membrane stiffness $A_{i j}$ & $8.22 \mathrm{E}+07$ & $1.39 \mathrm{E}+07$ & 0.00 & 0.00 & 0.00 & 0.00 \\
\cline { 2 - 7 } & $1.39 \mathrm{E}+07$ & $3.30 \mathrm{E}+07$ & 0.00 & 0.00 & 0.00 & 0.00 \\
\cline { 2 - 7 } & 0.00 & 0.00 & $1.48 \mathrm{E}+07$ & 0.00 & 0.00 & 0.00 \\
\hline \multirow{3}{*}{ Bending stiffness $D_{i j}$} & 0.00 & 0.00 & 0.00 & $3.11 \mathrm{E}+03$ & $5.20 \mathrm{E}+02$ & $0.00 \mathrm{E}+00$ \\
\cline { 2 - 7 } & 0.00 & 0.00 & 0.00 & $5.20 \mathrm{E}+02$ & $1.27 \mathrm{E}+03$ & $0.00 \mathrm{E}+00$ \\
\cline { 2 - 7 } & 0.00 & 0.00 & 0.00 & $0.00 \mathrm{E}+00$ & $0.00 \mathrm{E}+00$ & $5.55 \mathrm{E}+02$ \\
\hline
\end{tabular}

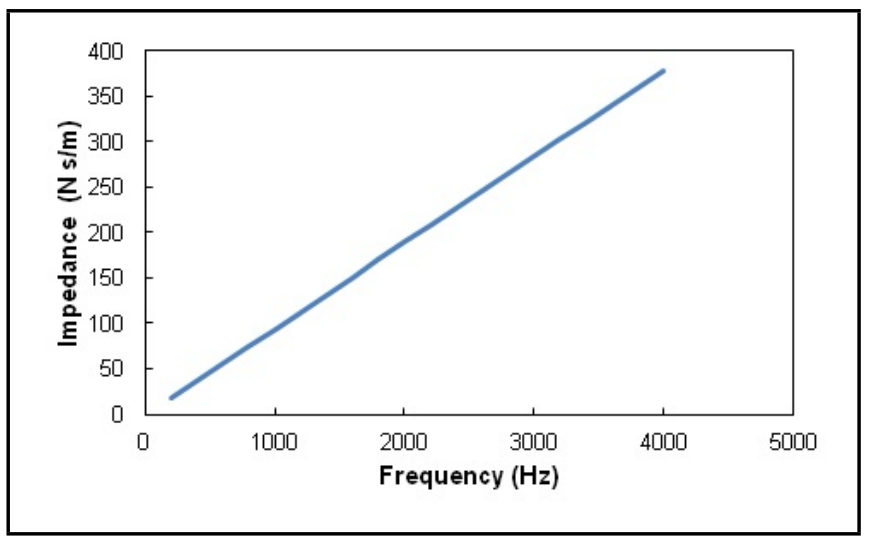

Figure 4. Impedance of the impedance head and the attachment elements.

measured force and the acceleration during the above test, the impedance of the impedance head was obtained and is given in Fig. 4. The reciprocal of the impedance gave the admittance. From the above results, the mass of the elements to be considered for determining the admittance using Eq. (4) was found to be $15 \mathrm{~g}$. These results were used in Eq. (9) to arrive at the correction factor that was applied on the measured admittance.

\subsection{Test Results}

The drive point admittance was obtained by measuring the force and acceleration at the driving point. The cross spectral densities of velocity and force were determined and then drive point admittance was obtained using Eq. (1). Actual admittance was then obtained from the measured admittance by accounting for the corrections. The cylinder was excited at 3 independent random locations (L1, L2, and L3) and the real part of the actual admittance are given in Table 4. Using Eq. (2), the modal density of the structure was then determined from the spatial average of the real part of the driving point admittances and the results are given in Table 4.

Clarkson, while deriving Eq. (2), pointed out that for its validity, there should be at least five modes in the frequency band of interest. ${ }^{21}$ It can be seen that there are more than 7 modes in the frequency band $500-700 \mathrm{~Hz}$ and beyond and hence, the modal density of this structure can be determined from the driving point admittance using Eq. (2).

In general, the driving point admittance varied with location. At low frequencies, the differences were expected to be larger, but at high frequencies, they did not vary much. One can see from the present results, given in Table 4, that in the
Table 4. Measured modal density

\begin{tabular}{||c|c|c|c|c|c||}
\hline \multirow{2}{*}{ Freq. (Hz) } & \multicolumn{4}{|c|}{ Real part of driving } & \multirow{2}{*}{$\begin{array}{c}\text { Modal } \\
\text { density } \\
\text { point admittance (m/N s) }\end{array}$} \\
\cline { 2 - 5 } & L1 & L2 & L3 & Avg. & (Hz) \\
\hline $300-500$ & 0.0007 & 0.0004 & 0.0007 & 0.0006 & 0.023 \\
\hline $500-700$ & 0.0010 & 0.0005 & 0.0013 & 0.0010 & 0.037 \\
\hline $700-900$ & 0.0016 & 0.0017 & 0.0016 & 0.0016 & 0.062 \\
\hline $900-1100$ & 0.0018 & 0.0027 & 0.0018 & 0.0021 & 0.081 \\
\hline $1100-1300$ & 0.0026 & 0.0027 & 0.0032 & 0.0028 & 0.108 \\
\hline $1300-1500$ & 0.0032 & 0.0023 & 0.0028 & 0.0028 & 0.108 \\
\hline $1500-1700$ & 0.0028 & 0.0036 & 0.0029 & 0.0031 & 0.119 \\
\hline $1700-1900$ & 0.0030 & 0.0041 & 0.0033 & 0.0035 & 0.135 \\
\hline $1900-2100$ & 0.0036 & 0.0032 & 0.0029 & 0.0032 & 0.123 \\
\hline $2100-2300$ & 0.0035 & 0.0026 & 0.0028 & 0.0030 & 0.114 \\
\hline $2300-2500$ & 0.0033 & 0.0026 & 0.0033 & 0.0031 & 0.118 \\
\hline $2500-2700$ & 0.0038 & 0.0034 & 0.0036 & 0.0036 & 0.139 \\
\hline $2700-2900$ & 0.0040 & 0.0042 & 0.0033 & 0.0039 & 0.148 \\
\hline $2900-3100$ & 0.0034 & 0.0039 & 0.0038 & 0.0037 & 0.143 \\
\hline $3100-3300$ & 0.0036 & 0.0035 & 0.0044 & 0.0039 & 0.148 \\
\hline $3300-3500$ & 0.0044 & 0.0035 & 0.0039 & 0.0040 & 0.152 \\
\hline $3500-3700$ & 0.0050 & 0.0040 & 0.0040 & 0.0044 & 0.167 \\
\hline $3700-3900$ & 0.0042 & 0.0049 & 0.0050 & 0.0047 & 0.182 \\
\hline $3900-4100$ & 0.0050 & 0.0050 & 0.0044 & 0.0048 & 0.184 \\
\hline
\end{tabular}

700-900 Hz band and beyond the driving point admittance did not vary much with location. In such cases, single point measurement itself can give a good estimate of modal density. This happens when the modal density is higher. It can be seen from the results that the mode count was greater than 12 beyond the 700-900 Hz band and the drive point admittance at individual positions did not vary significantly.

\subsection{Comparison with Theory}

Modal density was computed analytically using the expression given by (10)(see top of the page): ${ }^{19,20}$

Equation (10) neglected the transverse shear flexibility of the core. Modal density of composite sandwich cylinders considering transverse shear deformation was given by the following equation:

$$
\begin{aligned}
& n(f)=\frac{2 A f \rho}{N} \int_{0}^{\frac{\pi}{2}}\left\{\left(\frac{f_{2}}{f_{1}}+\sqrt{\left(\frac{f_{2}}{f_{1}}\right)^{2}+\frac{4 N^{2}}{f_{1}\left(\rho \omega^{2}-f_{3}\right)}}\right)\right. \\
& \left.-\frac{2 N^{2}}{f_{1}\left(\rho \omega^{2}-f_{3}\right) \sqrt{\left(\frac{f_{2}}{f_{1}}\right)^{2}+\frac{4 N^{2}}{f_{1}\left(\rho \omega^{2}-f_{3}\right)}}}\right\} d \theta
\end{aligned}
$$




$$
n(f)=\frac{A}{\pi} \sqrt{\rho} \int_{0}^{\frac{\pi}{2}} \frac{d \theta}{\left\{1-\frac{c^{4}\left(A_{11} A_{22}-A_{12}^{2}\right)}{4 \pi^{2} f^{2} \rho a^{2}\left(A_{11} c^{4}+A_{22} s^{4}+\frac{A_{11} A_{22}-A_{12}^{2}-2 A_{12} A_{66}}{A_{66}} c^{2} s^{2}\right)}\right\}^{\frac{1}{2}}\left\{D_{11} c^{4}+2\left(D_{12}+2 D_{66}\right) c^{2} s^{2}+D_{22} s^{4}\right\}^{\frac{1}{2}}} s .
$$

Table 5. Measured and estimated modal densities

\begin{tabular}{||c|c|c|c||}
\hline \multirow{2}{*}{ Frequency (Hz) } & \multicolumn{3}{|c|}{ Modal density (/Hz) } \\
\cline { 2 - 4 } & $\begin{array}{c}\text { Theory } \\
\text { (excl. shear) }\end{array}$ & $\begin{array}{c}\text { Theory } \\
\text { (incl. shear) }\end{array}$ & Expt. \\
\hline $300-500$ & 0.049 & 0.056 & 0.023 \\
\hline $500-700$ & 0.064 & 0.076 & 0.037 \\
\hline $700-900$ & 0.081 & 0.096 & 0.062 \\
\hline $900-1100$ & 0.104 & 0.124 & 0.081 \\
\hline $1100-1300$ & 0.123 & 0.146 & 0.108 \\
\hline $1300-1500$ & 0.100 & 0.128 & 0.108 \\
\hline $1500-1700$ & 0.093 & 0.127 & 0.119 \\
\hline $1700-1900$ & 0.091 & 0.129 & 0.135 \\
\hline $1900-2100$ & 0.091 & 0.132 & 0.123 \\
\hline $2100-2300$ & 0.089 & 0.136 & 0.114 \\
\hline $2300-2500$ & 0.087 & 0.140 & 0.118 \\
\hline $2500-2700$ & 0.086 & 0.144 & 0.139 \\
\hline $2700-2900$ & 0.087 & 0.149 & 0.148 \\
\hline $2900-3100$ & 0.086 & 0.154 & 0.143 \\
\hline $3100-3300$ & 0.086 & 0.159 & 0.148 \\
\hline $3300-3500$ & 0.086 & 0.165 & 0.152 \\
\hline $3500-3700$ & 0.085 & 0.170 & 0.167 \\
\hline $3700-3900$ & 0.083 & 0.176 & 0.182 \\
\hline
\end{tabular}

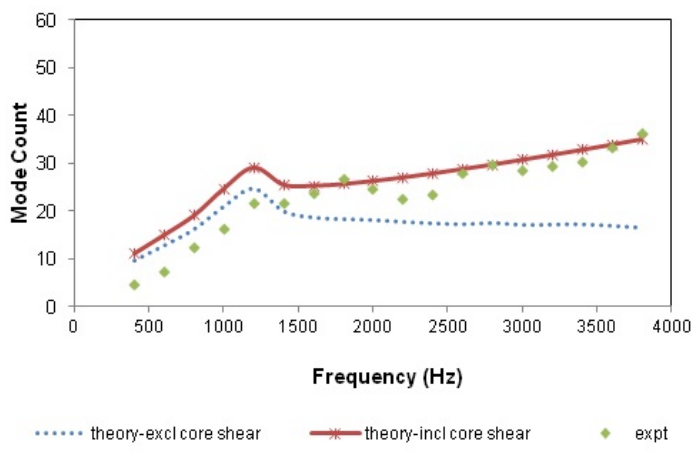

Figure 5. Mode-count of the cylinder.

where $f_{1}, f_{2}, f_{3}$ were functions of $\theta$ (given below) representing the orthotropic elastic properties.

$$
\begin{aligned}
& f_{1}=D_{11} c^{4}+2\left(D_{12}+2 D_{66}\right) c^{2} s^{2}+D_{22} s^{4} \\
& f_{2}=D_{11} c^{2}+D_{22} s^{2} ; \\
& f_{3}=\frac{\frac{\left(A_{11} A_{22}-A_{12}^{2}\right) c^{4}}{a^{2}}}{A_{11} c^{4}+A_{22} s^{4}+\frac{A_{11} A_{22}-A_{12}^{2}-2 A_{12} A_{66}}{A_{66}} c^{2} s^{2}} .
\end{aligned}
$$

The results are presented in Table 5 and Fig. 5. It was determined from the difference in the mode counts at the upper and lower frequency limit of the band.

It was interesting to see the result when the transverse shear deformation was neglected. The modal density estimated that neglecting the transverse shear deformation was very much low and the difference was significant at higher frequencies.
Once the transverse shear deformation was included, the theoretically estimated modal density was in very good agreement with the experimental results. The experimental results confirmed the need to incorporate the transverse shear deformation and validate the expression derived.

Modal densities of a typical composite cylinder were obtained experimentally. They were in good agreement with those estimated using theoretical expression. Though known theoretically, it was shown from the experiments that the modal densities of such cylinders were very much influenced by transverse shear deformation. ${ }^{20}$

\section{EXPERIMENTAL RESULTS WITHOUT CORRECTIONS}

The measured driving point admittance had to be corrected for the influence of the admittance of the impedance head and the attachment elements. This was first noticed by Clarkson and Pope ${ }^{22}$ and subsequently, a correction factor was proposed by Brown and Norton. ${ }^{25}$ Though it gave good results for thin isotropic structures, a modification as proposed by Renji was required for honeycomb sandwich panels. ${ }^{29}$ The results presented above were with the corrections factors derived by Renji. ${ }^{29}$ It was interesting to see the results if these correction factors were not applied.

Therefore, the modal densities were now determined without considering the correction factor, with the correction factor proposed by Brown and Norton ${ }^{25}$ and with the correction proposed by Renji, ${ }^{29}$ given in Table 6 and Fig. 6, along with the theoretically estimated modal densities. These results confirmed that the correction factor was essential and it also reinforced the need for considering $\operatorname{Img}\left(Y_{m}\right)$, which was the imaginary part of the measured admittance.

The experimental results confirmed the need for incorporating the correction factors based on the imaginary part of the measured driving point admittance with one more example. Also, the present work established the methodology of experimentally determining the modal densities in honeycomb sandwich-type structures, taking a composite honeycomb sandwich cylinder as an example. It is very important to state here that this is a good example where the experimental methodology was really driven by the results of theoretical predictions. The theoretically estimated modal densities were quite high compared to the experimentally obtained modal densities, when the admittance due to the impedance head was not considered. The theoretical prediction helped in investigating the reasons for these differences and arrived at suitable methodologies for determining the modal density experimentally. 
Table 6. Modal densities of cylinder with and without correction factors

\begin{tabular}{|c|c|c|c|c|c||}
\hline \multirow{2}{*}{ S1. No. } & \multirow{2}{*}{ Freq. (Hz) } & \multicolumn{5}{|c|}{ Modal density (/Hz) } \\
\cline { 3 - 6 } & & Without correction & correction with $\operatorname{Re}\left(Y_{m}\right)$ & correction including $\operatorname{Img}\left(Y_{m}\right)$ & Theory \\
\hline 1. & $300-500$ & 0.026 & 0.026 & 0.023 & 0.056 \\
\hline 2. & $500-700$ & 0.043 & 0.043 & 0.037 & 0.076 \\
\hline 3. & $700-900$ & 0.081 & 0.079 & 0.081 & 0.096 \\
\hline 4. & $900-1100$ & 0.117 & 0.107 & 0.108 & 0.124 \\
\hline 5. & $1100-1300$ & 0.166 & 0.133 & 0.108 & 0.146 \\
\hline 6. & $1300-1500$ & 0.161 & 0.123 & 0.119 & 0.128 \\
\hline 7. & $1500-1700$ & 0.193 & 0.122 & 0.123 & 0.127 \\
\hline 8. & $1700-1900$ & 0.200 & 0.111 & 0.114 & 0.132 \\
\hline 9. & $1900-2100$ & 0.190 & 0.099 & 0.118 & 0.136 \\
\hline 10. & $2100-2300$ & 0.198 & 0.091 & 0.139 & 0.140 \\
\hline 11. & $2300-2500$ & 0.204 & 0.083 & 0.148 & 0.144 \\
\hline 12. & $2500-2700$ & 0.168 & 0.078 & 0.143 & 0.149 \\
\hline 13. & $2700-2900$ & 0.141 & 0.072 & 0.148 & 0.154 \\
\hline 14. & $2900-3100$ & 0.123 & 0.067 & 0.152 & 0.159 \\
\hline 15. & $3100-3300$ & 0.106 & 0.062 & 0.167 & 0.165 \\
\hline 16. & $3300-3500$ & 0.091 & 0.057 & 0.182 & 0.170 \\
\hline 17. & $3500-3700$ & 0.071 & 0.050 & & 0.176 \\
\hline 18. & $3700-3900$ & 0.059 & 045 & & \\
\hline
\end{tabular}

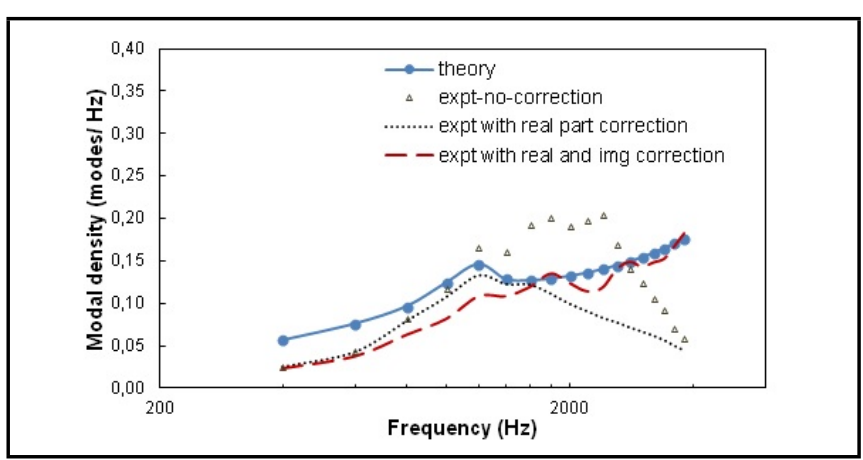

Figure 6. Modal density of the cylinder with and without correction factors.

\section{EXPERIMENTAL RESULTS FOR FREE CYLINDER}

The above experiments were conducted with the cylinder supported at two locations. Tests were then done with the cylinder in free condition. Test set-up and drive point location are shown in Fig. 7

The forces were measured by means of the impedance head. The mass of the impedance head and attachment elements were $15 \mathrm{~g}$. The test was repeated with two different drive points. The modal densities were obtained in the manner as done for the supported cylinder and the results are shown in Table 7. Figure 8 and Table 8 give a comparison of the modal densities when they were supported as well as when the edges were free along with the theoretically estimated modal densities.

The results showed that the modal densities in the free, as well as supported, cylinder (supported in between the edges) did not differ much and also, they were in agreement with the theoretically determined modal densities, which assumed simply supported conditions at the edges.

Though known theoretically, it was shown through the experiments on the practical structure that the modal densities in the higher order mode frequencies were not influenced by the boundary conditions.

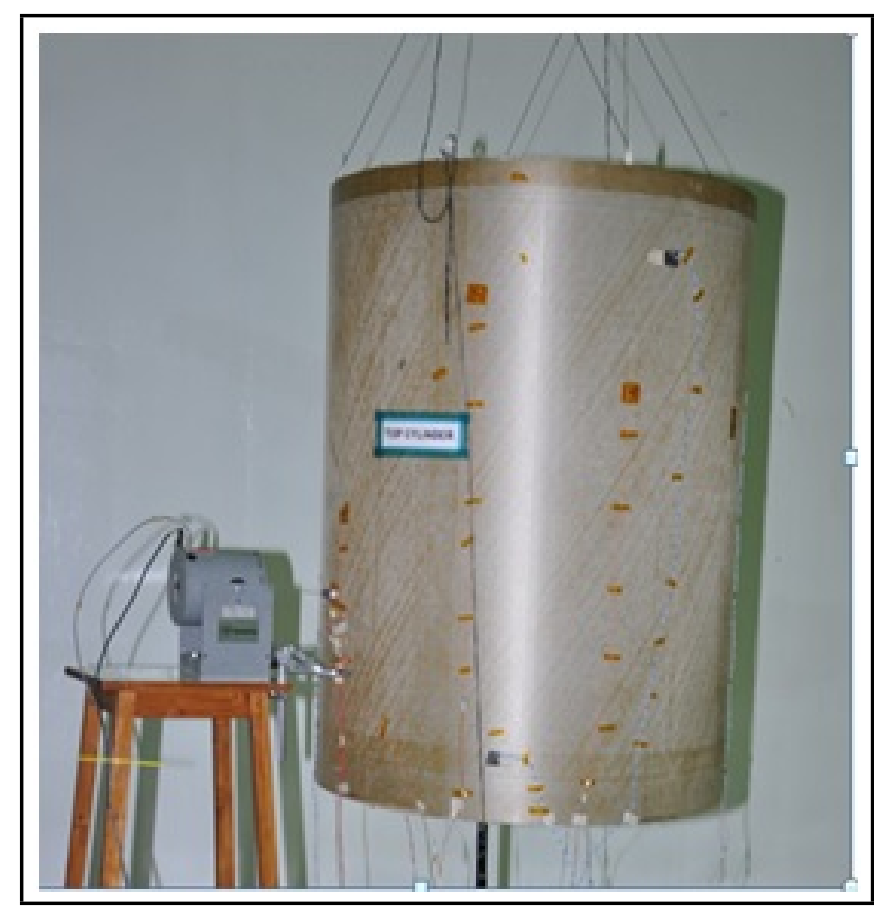

Figure 7. Test set-up and drive point location (Hung condition).

\section{MODAL DENSITIES AT HIGH FREQUENCIES}

The results presented above show that the experimental modal densities were in good agreement with those estimated theoretically. While deriving the expression for the modal density, both the face sheets were considered to be vibrating together and there was no independent motion of the face sheets. This was true at low frequencies. As the frequency increased, at a certain frequency, the wall of the honeycomb core cells in the honeycomb sandwich panels started vibrating, causing independent motions of the face sheets. The expression derived cannot be used to estimate the modal density beyond this frequency. In fact, beyond this frequency, there will not be any panel bending mode (a mode with both the face sheets bend- 
Table 7. Measured modal density of free cylinder.

\begin{tabular}{||c|c|c|c|c||}
\hline \multirow{2}{*}{ Freq. (Hz) } & \multicolumn{3}{|c|}{$\begin{array}{c}\text { Real part of driving } \\
\text { point admittance }(\mathrm{m} / \mathrm{N} \text { s) }\end{array}$} & \multirow{2}{*}{$\begin{array}{c}\text { Modal } \\
\text { density }(/ \mathrm{Hz})\end{array}$} \\
\cline { 2 - 4 } & L1 & L2 & Avg. & \multirow{2}{*}{} \\
\hline $300-500$ & 0.0004 & 0.0013 & 0.0010 & 0.036 \\
\hline $500-700$ & 0.0005 & 0.0011 & 0.0008 & 0.033 \\
\hline $700-900$ & 0.0017 & 0.0015 & 0.0016 & 0.063 \\
\hline $900-1100$ & 0.0027 & 0.0019 & 0.0023 & 0.090 \\
\hline $1100-1300$ & 0.0029 & 0.0034 & 0.0031 & 0.121 \\
\hline $1300-1500$ & 0.0026 & 0.0033 & 0.0030 & 0.114 \\
\hline $1500-1700$ & 0.0036 & 0.0034 & 0.0035 & 0.135 \\
\hline $1700-1900$ & 0.0042 & 0.0041 & 0.0041 & 0.158 \\
\hline $1900-2100$ & 0.0034 & 0.0036 & 0.0035 & 0.133 \\
\hline $2100-2300$ & 0.0028 & 0.0034 & 0.0031 & 0.121 \\
\hline $2300-2500$ & 0.0029 & 0.0041 & 0.0036 & 0.136 \\
\hline $2500-2700$ & 0.0037 & 0.0047 & 0.0042 & 0.161 \\
\hline $2700-2900$ & 0.0045 & 0.0044 & 0.0044 & 0.170 \\
\hline $2900-3100$ & 0.0042 & 0.0049 & 0.0046 & 0.176 \\
\hline $3100-3300$ & 0.0039 & 0.0056 & 0.0048 & 0.184 \\
\hline $3300-3500$ & 0.0039 & 0.0051 & 0.0045 & 0.173 \\
\hline $3500-3700$ & 0.0047 & 0.0048 & 0.0047 & 0.181 \\
\hline $3700-3900$ & 0.0061 & 0.0059 & 0.0060 & 0.231 \\
\hline
\end{tabular}

Table 8. Modal densities of the cylinder with different boundary conditions.

\begin{tabular}{|c|c|c|c|}
\hline \multirow{2}{*}{ Freq. (Hz) } & \multicolumn{3}{|c|}{ Modal density (/Hz) } \\
\cline { 2 - 4 } & Supported cylinder & Free cylinder & Theory \\
\hline $300-500$ & 0.023 & 0.036 & 0.056 \\
\hline $500-700$ & 0.037 & 0.033 & 0.076 \\
\hline $700-900$ & 0.062 & 0.063 & 0.096 \\
\hline $900-1100$ & 0.081 & 0.090 & 0.124 \\
\hline $1100-1300$ & 0.108 & 0.121 & 0.146 \\
\hline $1300-1500$ & 0.108 & 0.114 & 0.128 \\
\hline $1500-1700$ & 0.119 & 0.135 & 0.127 \\
\hline $1700-1900$ & 0.135 & 0.158 & 0.129 \\
\hline $1900-2100$ & 0.123 & 0.133 & 0.132 \\
\hline $2100-2300$ & 0.114 & 0.121 & 0.136 \\
\hline $2300-2500$ & 0.118 & 0.136 & 0.140 \\
\hline $2500-2700$ & 0.139 & 0.161 & 0.144 \\
\hline $2700-2900$ & 0.148 & 0.170 & 0.149 \\
\hline $2900-3100$ & 0.143 & 0.176 & 0.154 \\
\hline $3100-3300$ & 0.148 & 0.184 & 0.159 \\
\hline $3300-3500$ & 0.152 & 0.173 & 0.165 \\
\hline $3500-3700$ & 0.167 & 0.181 & 0.170 \\
\hline $3700-3900$ & 0.182 & 0.231 & 0.176 \\
\hline
\end{tabular}

ing together), instead, only the face sheet bending mode (a face sheet alone bending) will be present.

It was now explored whether this frequency could be theoretically determined. The honeycomb core used in the cylinder had a thickness of 18 microns and the size of the cell wall is $2.8 \mathrm{~mm} \times 12 \mathrm{~mm}$. The fundamental frequency of the wall of the core was calculated to be $5800 \mathrm{~Hz}$ considering it as a plate, using the relation:

$$
f=\pi^{2} \times\left[1+\left(\frac{a}{b}\right)^{2}\right] \frac{1}{2 \pi} \sqrt{\frac{D}{\rho a^{4}}} .
$$

Hence, treating the honeycomb sandwich as a whole will not be correct at frequencies beyond approximately $5800 \mathrm{~Hz}$, and one has to consider the two face sheets as independent plates. There will not be any panel bending mode beyond $5800 \mathrm{~Hz}$. It is to be noted that the frequency of the cell wall vibration de-

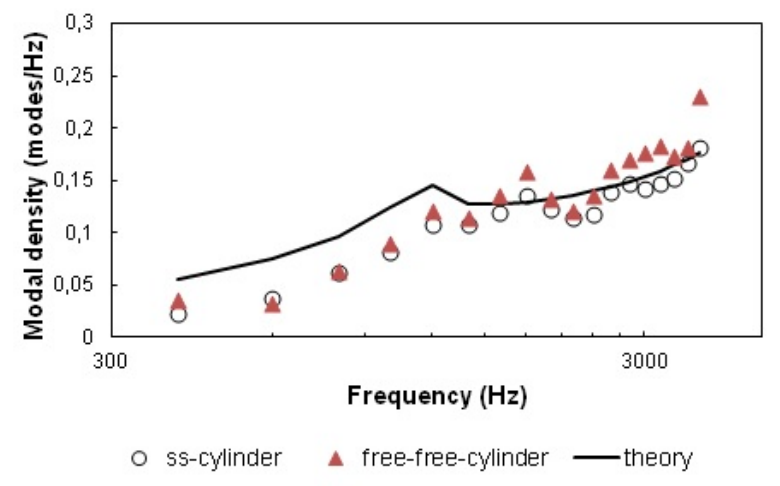

Figure 8. Effect of boundary conditions on the modal density.

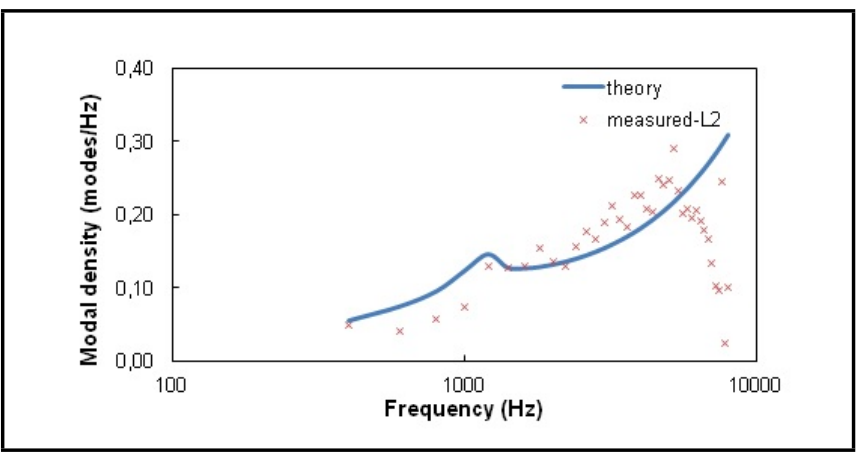

Figure 9. Modal density of the cylinder at high frequencies.

termined here is only an approximation and it should be taken as an indicative value to explain the phenomenon.

It was interesting to study the experimental modal densities at higher frequencies and see what impact was made when the core cells vibrated. The modal densities were now determined at frequencies above $4000 \mathrm{~Hz}$ (with one driving point-L2) and the results are given in Table 9 and Fig. 9.

It can be seen that there was a sharp reduction in the experimental modal densities, actually the measured admittance values, of the cylinder beyond $5400 \mathrm{~Hz}$. It was calculated and shown before that at frequencies around $5800 \mathrm{~Hz}$, the cell walls started resonating. Beyond this frequency, it was expected that the two face sheets would vibrate independently, and the modes encountered then were the bending modes of the face sheets.

The driving point admittance of a thin plate was very high compared to a honeycomb sandwich-type structure and it can be estimated using the equation:

$$
R e(Y)=\frac{1}{8} \frac{1}{\sqrt{D \rho}}
$$

where $D$ was the flexural rigidity and $\rho$ was the mass per unit area of the plate. For the honeycomb sandwich cylinder considered in this work, the driving point admittance of the cylinder, say at $4000 \mathrm{~Hz}$, was about $0.005 \mathrm{~m} / \mathrm{N} \mathrm{s}$ (refer Table 4). The driving point admittance of the face sheet alone vibrating was approximately $0.35 \mathrm{~m} / \mathrm{N} \mathrm{s}$. The modal density as well as the driving point admittance significantly increased at frequencies beyond $5400 \mathrm{~Hz}$ from what these values were before $5400 \mathrm{~Hz}$.

But the admittance was measured using an impedance head. 
Table 9. Modal densities of the cylinder at high frequencies

\begin{tabular}{|c|c|c|c|}
\hline Sl. No & Frequency $(\mathrm{Hz})$ & $\operatorname{Re}\left(Y_{a}\right)(\mathrm{m} / \mathrm{N} \mathrm{s})$ & Modal density $(/ \mathrm{Hz})$ \\
\hline 1 & $300-500$ & 0.0013 & 0.050 \\
\hline 2 & $500-700$ & 0.0011 & 0.042 \\
\hline 3 & $700-900$ & 0.0015 & 0.059 \\
\hline 4 & $900-1100$ & 0.0019 & 0.074 \\
\hline 5 & $1100-1300$ & 0.0034 & 0.131 \\
\hline 6 & $1300-1500$ & 0.0033 & 0.128 \\
\hline 7 & $1500-1700$ & 0.0034 & 0.131 \\
\hline 8 & $1700-1900$ & 0.0041 & 0.156 \\
\hline 9 & $1900-2100$ & 0.0036 & 0.138 \\
\hline 10 & $2100-2300$ & 0.0034 & 0.132 \\
\hline 11 & $2300-2500$ & 0.0041 & 0.157 \\
\hline 12 & $2500-2700$ & 0.0047 & 0.178 \\
\hline 13 & $2700-2900$ & 0.0044 & 0.168 \\
\hline 14 & $2900-3100$ & 0.0049 & 0.190 \\
\hline 15 & $3100-3300$ & 0.0056 & 0.214 \\
\hline 16 & $3300-3500$ & 0.0051 & 0.194 \\
\hline 17 & $3500-3700$ & 0.0048 & 0.184 \\
\hline 18 & $3700-3900$ & 0.0059 & 0.227 \\
\hline 19 & $3900-4100$ & 0.0060 & 0.228 \\
\hline 20 & $4100-4300$ & 0.0054 & 0.208 \\
\hline 21 & $4300-4500$ & 0.0053 & 0.205 \\
\hline 22 & $4500-4700$ & 0.0065 & 0.250 \\
\hline 23 & $4700-4900$ & 0.0063 & 0.243 \\
\hline 24 & $4900-5100$ & 0.0065 & 0.248 \\
\hline 25 & $5100-5300$ & 0.0076 & 0.293 \\
\hline 26 & $5300-5500$ & 0.0061 & 0.235 \\
\hline 27 & $5500-5700$ & 0.0053 & 0.204 \\
\hline 28 & 5700-5900 & 0.0054 & 0.209 \\
\hline 29 & $5900-6100$ & 0.0051 & 0.196 \\
\hline 30 & $6100-6300$ & 0.0054 & 0.207 \\
\hline 31 & $6300-6500$ & 0.0050 & 0.192 \\
\hline 32 & $6500-6700$ & 0.0047 & 0.181 \\
\hline 33 & $6700-6900$ & 0.0044 & 0.168 \\
\hline 34 & $6900-7100$ & 0.0035 & 0.134 \\
\hline 35 & $7100-7300$ & 0.0027 & 0.103 \\
\hline 36 & $7300-7500$ & 0.0025 & 0.097 \\
\hline 37 & $7500-7700$ & 0.0065 & 0.249 \\
\hline 38 & $7700-7900$ & 0.0006 & 0.022 \\
\hline 39 & $7900-8100$ & 0.0026 & 0.101 \\
\hline
\end{tabular}

The value of the admittance of the impedance head at $4000 \mathrm{~Hz}$ was $0.0027 \mathrm{~m} / \mathrm{N}$ s. The admittance of the impedance head acted in parallel to the driving point admittance and the resultant admittance (measured) will be lower than the actual admittance. ${ }^{25}$ At $4000 \mathrm{~Hz}$, the driving point admittance was $0.0050 \mathrm{~m} / \mathrm{N} \mathrm{s}$ whereas the admittance due to impedance head was $0.0027 \mathrm{~m} / \mathrm{N} \mathrm{s}$. When the face sheet alone vibrated, the driving point admittance at $5400 \mathrm{~Hz}$ was $0.35 \mathrm{~m} / \mathrm{N}$ s whereas the admittance due to impedance head was $0.0020 \mathrm{~m} / \mathrm{N} \mathrm{s}$. As they are in parallel, at frequencies beyond $5400 \mathrm{~Hz}$, where the face sheet alone vibrated, the admittance being measured was mainly the admittance of the impedance head, which decreased as frequency increased.

Therefore, at higher frequencies, the two face sheets of the honeycomb sandwich-type structure vibrated independently. ${ }^{29}$ The frequency at which this phenomenon started occurring can be approximately estimated from the natural frequency of the wall of the honeycomb core. Beyond this frequency, there was a sharp reduction in the measured admittance and hence, the measured modal density, and they were erroneous. These characteristics could be utilized in experimentally determining this frequency.

\section{CONCLUSIONS}

Modal densities of a typical honeycomb sandwich composite cylinder are obtained experimentally from the real part of the drive point admittance. Correction factors that are considering the imaginary part of the measured admittance are applied to determine the actual admittance. Modal densities of the cylindrical shell are theoretically estimated using the expression that incorporates the transverse shear deformation. A very good agreement between the theory and the experiment is seen and it confirms the validity of the expression, as well as the need for including the transverse shear deformation for such cylindrical shells. The results also confirm the importance of correction factors and the need for measuring the imaginary part of the admittance. The experimental results also demonstrate the fact that the modal densities in the higher order mode frequencies are independent of the boundary conditions. At higher frequencies, the face sheets vibrate independently. The frequency beyond which it occurs is the natural frequency of the wall of the honeycomb core. Beyond this frequency, the measured admittance is in large error, what is being measured is the admittance of the impedance head. There is a sharp reduction in the measured admittance around this frequency and this feature can be utilized in experimentally determining the frequency beyond which the face sheets vibrate independently.

\section{REFERENCES}

1 Lyon RH, Statistical Energy Analysis of Dynamical Systems: Theory and Applications, MIT Press, Cambridge, MA, (1975).

2 Norton MP, Fundamentals of Noise and Vibration Analysis for Engineers, Cambridge University Press, England, (1989).

3 Cotoni, V., Langley, R. S., and Shorter, P. J. A statistical energy analysis subsystem formulation using finite element and periodic structure theory, Journal of Sound and Vibration, 318(4-5), 1077-1108, (2008). https://dx.doi.org/10.1016/j.jsv.2008.04.058

${ }^{4}$ Culla, A., D’Ambrogio, W., Fregolent, A., and Milana, S. Vibroacoustic optimization using a statistical energy analysis, Journal of Sound and Vibration, 375, 102-114, (2016). https://dx.doi.org/10.1016/j.jsv.2016.04.026

5 Wilkinson J. P. D. Modal densities of certain shallow structural elements, Journal of Acoustical society of America, 43, 245-251, (1968). https://dx.doi.org/10.1121/1.1910773

${ }^{6}$ Hart, F. D. and Shah, C. G. NASA CR-(1773), Compendium of Modal densities for structures, 1971.

7 Szechenyi, E. Modal densities and radiation efficiencies of unstiffened cylinders using statistical methods, 
Journal of Sound and Vibration, 19(1), 65-81, (1971). https://dx.doi.org/10.1016/0022-460X(71)90423-8

${ }^{8}$ Langley, R. S. The modal density and mode count of thin cylinders and curved panels, Journal of Sound and Vibration, 169(1), 43-53, (1994). https://dx.doi.org/10.1006/jsvi.1994.1005

9 Maymon, G. Modal densities of stiffened, axially loaded cylindrical shells, Journal of Sound and Vibration, 42(1), 115-127, (1975). https://dx.doi.org/10.1016/0022$460 \times(75) 90306-5$

10 Ramachandran, P., and Narayanan, S. Evaluation of modal density, radiation efficiency and acoustic response of longitudinally stiffened cylindrical shell, Journal of Sound and Vibration, 304(1-2), 154-174, (2007). https://dx.doi.org/10.1016/j.jsv.2007.02.020

11 Finnveden, S. Evaluation of modal density and group velocity by a finite element method Journal of Sound and Vibration, 273(1-2), 51-75, (2004). https://dx.doi.org/10.1016/j.jsv.2003.04.004

12 Elliott, G. H. The evaluation of the modal density of paraboloidal and similar shells, Journal of Sound and Vibration, 19(3), 477-483, (1988). https://dx.doi.org/0.1016/0022-460X(88)90225-8

13 Williams, F.W. and Banerjee J. R. Accurately computed modal densities for panels and cylinders including corrugations and stiffeners, Journal of Sound and Vibration, 93(4), 481-488, (1984). https://dx.doi.org/10.1016/0022$460 X(84) 90417-6$

14 Farshidianfar, M. H., Farshidianfar, A., and Moghadam, M. M. Mode count and modal density of isotropic circular cylindrical shells using a modified wavenumber space integration method Journal of Vibration and Acoustics, 136(4), (2014).https://dx.doi.org/10.1115/1.4027212

15 Elishakoff, I. Distribution of natural frequencies in certain structural elements, Journal of Acoustical Society of America, 57, 361-369, (1975). https://dx.doi.org/10.1121/1.380449

16 Langley, R. S. The modal density of anisotropic structural components. Journal of Acoustical Society of America, 99, 3481-3487, (1996). https://dx.doi.org/10.1121/1.415218

17 Chronopoulos, D., Troclet, B., Ichchou, M., and Laine, J. P. A unified approach the broadband vibroacoustic response of composite shells, Composites Part.B: Engineering, 43(4), 1837-1846, (2012). https://dx.doi.org/10.1016/j.compositesb.2012.01.059

${ }^{18}$ Chronopoulos, D., Ichchou, M., Troclet, B., and Bareille, O. Predicting the broadband response of a layered cone-cylinder-cone shell, Composite Structures, 107, 149-159, (2014). https://dx.doi.org/10.1016/j.compstruct.2013.07.055
${ }^{19}$ Florence, S. J. K., and Renji, K. Modal density of thin composite cylindrical shells, Journal of Sound and Vibration, 365, 157-171, (2016). https://dx.doi.org/10.1016/j.jsv.2015.11.030

${ }^{20}$ Florence, S. J. K., Renji, K. and Subramanian, K. Modal density of honeycomb sandwich composite cylindrical shells considering transverse shear deformation, International Journal of Acoustics and Vibration, 23(1), 83-92, (2018). https://dx.doi.org/10.20855/ijav.2018.23.11241

${ }^{21}$ Clarkson, B. L. The derivation of modal densities form point impedances, Journal of Sound and Vibration, 77, 583-584, (1981).

${ }^{22}$ Clarkson, B. L., and Pope, R. J. Experimental determination of modal densities and loss factors of flat plates and cylinders, Journal of Sound and Vibration, 77, 535-549, (1981). https://dx.doi.org/10.1016/S0022-460X(81)80049-1

${ }^{23}$ Clarkson, B. L., and Pope, R. J. Experimental determination of vibration parameters required in statistical energy analysis method, transactions of the ASME, Journal of Vibration, Acoustics, Stress and Reliability in Design,105(3), 337-344, (1983). https://dx.doi.org/10.1115/1.3269111

${ }^{24}$ Brown, K. T. Measurement of modal density: An improved technique for use on lightly damped structures, Journal of Sound and Vibration, 96(1), 127-132, (1984). https://dx.doi.org/10.1016/0022-460X(84)90599-6

25 Brown, K. T. and Norton, M. P. Some comments on the experimental determination of modal densities and loss factors for statistical energy analysis applications, Journal of Sound and Vibration, 102(4), 588-594, (1985). https://dx.doi.org/10.1016/S0022-460X(85)80118-8

${ }^{26}$ Clarkson, B. L., and Ranky, M.F. Modal density of honeycomb plates, Journal of Sound and Vibration, 91(1), 103-118, (1983). https://dx.doi.org/10.1016/0022$460 X(83) 90454-6$

${ }^{27}$ Ferguson, N. S., and Clarkson, B. L. The modal density of honeycomb shells, Transactions of the ASME, Journal of Vibration, Acoustics, Stress and Reliability in Design, 108(4), 399-404, (1986). doi10.1115/1.3269362

${ }^{28}$ Renji, K., Nair, P. S., and Narayanan, S. Modal density of composite honeycomb sandwich panels, Journal of Sound and Vibration, 195(5), 687-699, (1996). https://dx.doi.org/10.1006/jsvi.1996.0456

${ }^{29}$ Renji, K. Experimental modal densities of honeycomb sandwich panels at high frequencies, Journal of Sound and Vibration, 237(1), 67-79, (2000). https://dx.doi.org/10.1006/jsvi.2000.3026 